\title{
ENTRE LIVROS E O ROÇADO: TRAJETÓRIAS EDUCACIONAIS NO ASSENTAMENTO JOÃO CANUTO-PA'
}

\author{
Recebido em 29/11/2020, aprovado em 11/03/2020 \\ 10.30612/mvt.v6i11.10759 \\ Andrey Minin Martin² \\ Geiziane A. Silva ${ }^{3}$
}

\begin{abstract}
RESUMO: Este trabalho tem como objetivo analisar as práticas educacionais no campo partir das experiências da Escola Municipal de Ensino Fundamental Dom José Gomes, localizada no assentamento João Canuto, no município de Xinguara/PA. A partir de uma pesquisa qualitativa, foram realizados estudos de campo e entrevistas com sujeitos que vivenciaram tais trajetórias, e ainda vivenciam, no processo de construção da educação no campo, tais como os educadores que atuam na escola, bem como os moradores deste assentamento. Conjuntamente, foram analisados o mote documental de materiais didáticos utilizados no processo de ensino, tendo centralidade a coleção Novo Girassol: Saberes e Fazeres do Campo (PNLD 2016/2018), suas práticas e usos. Através da metodologia da história oral e diálogo com autores sobre educação no campo e ensino de história buscamos entender como novas práticas educativas foram gestadas neste processo de luta, pautadas na emancipação dos sujeitos, reafirmação de suas identidades e na valorização de saberes centrais para permanência dos homens e mulheres no campo.
\end{abstract}

Palavras-chave: Educação do/no campo; Assentamento João Canuto; Escola Dom José Gomes.

\section{BETWEEN BOOKS AND THE SWIDDEN: EDUCATIONAL TRAJECTORIES IN THE JOÃO CANUTO SETTLEMENT-PA}

ABSTRACT: This work aims to analyze the educational practices in the rural area from the experiences of Dom José Gomes Primary Municipal School, located at João Canute settlement in Xinguara/ PA. Through a qualitative research, field studies and interviews were carried out with subjects who experienced such trajectories, and who are still experiencing this process of building education in the field, such as the school teachers of this settlement and its residents. School archives and teaching

\footnotetext{
1 Assentamento leva o nome do presidente do Sindicato dos Trabalhadores Rurais de Rio Maria-Pará, assassinado no dia 18 de dezembro de 1985, em razóes dos conflitos agrários na região.

2 Doutor em História-Unesp. Professor adjunto da Universidade Federal do Sul e Sudeste do Pará-Unifesspa. andrey@unifesspa. edu.br.

3 Graduada em História pela Universidade Federal do Sul e Sudeste do Pará. geizianeamaral2@gmail.com
} 
materials from the collection Novo Girassol: Saberes e Fazeres do Campo (PNLD 2016/2018) its practices and uses. Using oral history as the methodology and dialogue with a motto of authors this paper tries to understand how new educational practices were born in this process of struggle, guided in the emancipation of the subjects, reaffirmation of their identities and the valorization of central knowledge for the permanence of the men and women in the field.

Keywords: Education of/in the field, João Canuto Settlement, Dom José Gomes School.

\section{ENTRE LOS LIBROS Y EL SWIDDEN: TRAYECTORIAS EDUCATIVAS EN EL ASSENTAMIENTO JÕAO CANUTO-PA}

RESUMEN: Esta obra tiene como objetivo analizar las prácticas educativas de/en el campo a partir de las experiencias de la Escuela Municipal de Primaria Dom José Gomes, ubicada en el asentamiento de Joao Canuto, en el municipio de Xinguara /PA. A partir de una investigación cualitativa, se realizaron estudios de campo y entrevistas con temas que experimentaron tales trayectorias, $y$ todavía experiencia en el proceso de construcción de la educación en el campo, como los educadores que trabajan en la escuela, así como los residentes de este asentamiento. Juntos, se analizó el lema documental de los materiales didácticos utilizados en el proceso de enseñanza, con la centralidad de la colección Novo Girassol: Saberes y Fazeres do Campo (PNLD 2016/2018) sus prácticas y usos. A través de la metodología de la historia oral y el diálogo con autores sobre la educación en el campo buscamos comprender cómo se crearon nuevas prácticas educativas en este proceso de lucha, basado en la emancipación de los sujetos, la reafirmación de sus identidades y la valorización del conocimiento central para la fijación del hombres y mujeres en el campo.

Palavras Clave: Educación de/en el campo, Asentamiento Joao Canuto, Escuela Don José Gomes.

\section{INTRODUÇÃO}

Escrever sobre o campo e suas plurais manifestações sociais torna-se neste trabalho uma tarefa plural, pois falar destas práticas se confundem, em muitas situaçóes, com trajetória e vivência apreendidas. Viver e crescer no meio rural em nosso país é carregar estigmas entre lutas e resistências e poder falar de práticas e experiências sobre a educação no campo não seria diferente.

O objetivo deste trabalho é promover uma reflexão sobre a educação no campo no Sul e Sudeste do Pará a partir das experiências da Escola Municipal de Ensino Fundamental Dom José Gomes, localizada no assentamento João Canuto3 município de Xinguara/PA. Busca-se entender as trajetórias organizativas na luta pela sua criação e estruturação, bem como analisar a estruturação e as práticas educacionais na escola existente neste assentamento. Apesar de sua localização no município de Xinguara, sua base burocrática está vinculada ao município de Sapucaia, no mesmo estado, devido a ligaçáo social dos sujeitos que compóem o assentamento com este município, o que motivou um acordo entre as prefeituras. 
Observamos que, de modo geral, a educação no campo ainda não possui centralidades na forma como é posta em práticas em distintas localidades do país. Como pontuam autores como Caldart (2011) e Molina (2006) a legislação nas últimas décadas tem ampliado e reconhecido a necessidade de novos olhares para tal aparato diversificado do meio rural, mas em sua maioria os materiais e a forma como tal educação são ofertadas acabam sendo simplesmente a reproduçáo do próprio modelo ofertado nas escolas urbanas, não adequados a estas necessidades. São questóes que dever ser (re) pensadas, pois não levam em consideração os saberes e necessidades da vida camponesa, descontextualizando a sua realidade e não se conectando as suas bases educacionais.

\section{EDUCAÇÃO DO/NO: TRAJETÓRIAS, LUTAS E CONQUISTAS}

O ensino público brasileiro, de maneira geral, foi marcado historicamente por um imenso descaso governamental, ficando sempre em segundo plano na pauta de investimentos financeiros em políticas públicas para sua melhoria. Além disso, o modelo de ensino adotado procurava, e ainda procura, atender os interesses do grande capital, ou seja, o ensino oferecido serve para capacitar trabalhadores e trabalhadoras para atenderem as demandas do mercado de trabalho.

E como nossa própria estruturação do ensino no campo acabou transformando-se uma "extensão" de práticas urbanas, no que diz respeito ao ensino ofertado às populaçóes que vivem áreas rurais, esse descaso foi ainda maior, conforme assevera Leite (1996), no qual "a educação rural no Brasil, por motivos socioculturais, sempre foi relegada a planos inferiores [...]", tendo como respaldo o discurso ideológico proferido pelas as oligarquias agrárias de "que pessoas da roça não necessitavam de estudo". E foi com base nesse discurso que por várias décadas a educação rural se estruturou.

Para Passador (2003), práticas governamentais educativas no campo brasileiro remontam o início do século XIX, em que sua história está relacionada ao próprio estabelecimento da República:

O ensino agrícola nasceu em 1889 com a proclamação da República e a criação, pelo o governo, da pasta da agricultura, comercio e indústria. Apesar de naquela época, a atividade econômica brasileira se constituir na agricultura, entre $1894 \mathrm{e}$ 1906 o setor foi suprimido. Somente em 1909 foi novamente instalada e então foram criadas as instituiçóes de ensino voltadas para estudos agronômicos. Mas a educação pública toma contornos efetivamente nacionais nos anos 30 , com a criação do ministério da educaçáo. (2003, p. 88).

Segundo Calazans (1993), as primeiras propostas de escolarização das populaçôes rurais foram implantadas no século de XIX, porém, foram somente a partir da década de 30 do século XX, que elas ganharam maior visibilidades. Em específico a partir do lançamento do Manifesto dos Pioneiros:

Em 1932, foi lançado o Manifesto dos Pioneiros da Educação Nova, que buscava diagnosticar e sugerir rumos às políticas públicas de educação e preconizava a organizaçáo de uma escola democrática, que proporcionasse as mesmas oportunidades para todos e que, sobre a base de uma cultura geral comum, possibilitasse especializaçóes para as atividades de preferência intelectual 
(humanidades e ciências) ou de preponderância anual e mecânica (cursos de caráter técnico) agrupadas em: extração de matérias-primas agricultura, minas e pesca; elaboração de matérias-primas - indústria; distribuiçáo de produtos elaborados - transportes e comércio. Nessa proposta, as demandas do campo e da cidade eram igualmente consideradas e contempladas. (BRASIL, 2007, p.10).

De acordo com Leite (1996), essas primeiras propostas de implantação de uma educação do/no campo surgiram para conter intenso fluxo migratório de rurícolas para os grandes centros urbanos, onde o processo de industrializaçáo já se encontrava bastante avançado. Ainda de acordo com o autor os investimentos em programas de escolarização das populaçôes rurais tiveram como fator a fixação dos camponeses no campo, evitando sua migração em massa para os grandes centros. Para a demanda necessária para outras atividades no campo tal canal educacional visou, bem intimamente, qualificá-los para o mercado de trabalho, visando assim alfabetizar esses sujeitos, ensinando-os a ler, escrever e apreender outros conhecimentos básicos.

Logo, o que se observa ao longo do século XX é que, entre avanços e recuos, a educação do campo não necessitava da estruturação e embasamento oferecido em outros espaços, como o urbano. Era comum evidenciar escolas funcionando somente em salas multisseriadas, não atendendo as demandas estabelecidas desde a década de 1930, nem tanto sendo reconhecidos oficialmente para o egresso nas séries subsequentes. Mesmo com os avanços estabelecidos pela Lei de no 4.024/1961, como a estruturação do ensino básico e a preocupação em criar núcleos educacionais no campo, somente após a constituição de 1988 que iríamos assistir a novas propostas para esta modalidade de ensino. O Artigo $3^{\circ}$ da Constituição Federal (1988) trata dos objetivos fundamentais que foram constituídos para a república federativa brasileira, dos quais os incisos III e IV poderão contribuir com as análises ligadas à construção da educação do campo, quando se trata da erradicação da pobreza, das desigualdades sociais, e em promover o bem de todos sem preconceitos e discriminação. O Artigo $5^{\circ}$ em seu caput trata da igualdade de todos perante a lei, o que para Duarte (2008) constitui o princípio fundamental do Estado Liberal de Direito. Consiste no reconhecimento da noção de que todos os seres humanos são sujeitos de direitos, independentemente de quaisquer características que os especifiquem ou diferenciem.

Na década de 1990, de forma geral, os movimentos sociais do campo, fortalecidos pós-regime militar, começaram a discutir e articular a criação do movimento denominado "Por uma Educação Básica do Campo", se materializando em eventos como o "10 Encontro Nacional de Educadoras e Educadores da Reforma Agrária (ENERA)", ocorrido em Julho de 1997 e a "I Conferência Nacional por uma Educação Básica do Campo”, em Luziânia Goiás (CNEC), em 1998. Após a realização desses encontros educadores e representantes de diversos grupos ligados ao campo começaram a formular documentos que denunciavam o descaso com a educaçáo e a elaborar estudos com objetivos a atender as necessidades específicas da população ligada ao campo. Os envolvidos começaram a pensar em propostas para mudar essa realidade.

A LDB, de 1996, já apresentava e reconhecia em seu texto a diversidade sociocultural como um dos elementos na construção de diretrizes próprias para a educação no campo, assim como as Diretrizes Curriculares Nacionais para Educação Básica. Por tais diretrizes não se deve apenas "adaptar" mas adequar a tais estruturas e suas especificidades, tais como calendários próprios, ligados as formas e períodos de trabalho e possíveis condiçóes climáticas, estabelecendo a garantia de acesso e permanência no processo educacional. Outra conquista pelo qual se materializaram tais 
possibilidades foi pela aprovação das Diretrizes Operacionais para a Educação Básica das Escolas do Campo, em 2001, marco no processo de fixação e expansão da educação do/no campo. Elementos como a formação diferenciada de professores, adequação de conteúdos e práticas pedagógicas contextualizadas tornaram-se pautas importantes nesta trajetória.

De acordo Munarim (2008), a questão educação no campo "é pressuposto básico que os povos do campo não prescindem do direito à igualdade, na mesma medida que, ao cultivarem identidades próprias, são sujeitos de direito ao trato diferenciado" (p, 54). A educação deve ser universal e atender as diversidades étnico-culturais em toda sua forma de existência, pois se entende por "povos do campo" todas as populaçóes cujas suas identidades estejam ligadas a natureza podendo estes pertencer aos diversos grupos ou "espaços sócio geográficos de igual apelo cultural e de produção de vida”. A educação do/no campo nasceu com o apoio de movimentos sociais que entendem o quanto ela é fundamental para permanência do homem no campo. Através da educação as populaçóes ligadas a terra poderão melhor compreender o processo político, econômico e social do país, o que possibilitará melhores condiçôes de vida a essa população e também conhecimento necessários às reivindicaçóes de seus direitos, considerando que o berço da Educação no campo é a participação popular.

Logo, como um dos principais desdobramentos destes eventos e movimentos reivindicatórios foi a criação do Programa Nacional de Educação na Reforma Agrária (Pronera), em 1998, focado diretamente em uma política de assistência educacional para o campo, especificamente para os assentamentos de reforma agrária . Inicialmente, o programa teve como foco a Educação de Jovens e Adultos, EJA, sendo gradualmente estruturado etapas da Educação Básica I, contando atualmente inclusive com experiencias de ensino superior. Interessante observar que as principais parcerias que foram estabelecidas para que este programa tivesse êxito foram os movimentos sociais, entidades como a Comissão Pastoral da Terras, a CPT, governos municipais e estaduais e instituiçôes públicas de ensino.

Assim, corroboramos com as palavras de Caldart (2008) quando pontua que pensar a educação no campo é apreender não somente as práticas e saberes locais, mas uma "disputa de território imateriais", pois "educação do campo é um conceito em movimento como todos os conceitos, mas ainda mais porque busca apreender um fenômeno em fase de constituição histórica; por sua vez, a discussão conceitual também participa deste movimento da realidade” (p. 70).

\section{ASSENTAMENTO JOÃO CANUTO E A ESCOLA DOM JOSÉ GOMES}

A trajetória do campo na regiáo sul e sudeste do Pará não se diferencia totalmente das questão de nossa história: uma gama de problemáticas para vida e permanência de uma diversidade de sujeitos que na terra queriam viver e permanecer. Da lei de terras no século XIX aos sancionamentos legislativos da década de 1960 (como a Lei n.o 4.504, nomeada como Estatuto da Terra) passando pelas mudanças em nossa última constituição, por mais que avanços possam ser apontados, a verdade é que a reforma agrária nunca foi uma prioridade em nosso país. Isto pelo menos para nossas

4 Criado por meio da Portaria n 10/98, o objetivo do programa é "fortalecer a educação nas áreas de Reforma Agrária estimulando, propondo, criando, desenvolvendo e coordenando projetos educacionais, utilizando metodologias voltadas para a especificidade do campo tendo em vista contribuir para a promoção do desenvolvimento sustentável”. (PRONERA, Manual de Operaçóes, 2004, p. 17) 
elites que ainda controlam o jogo político, porque esta mesma gama de sujeitos nunca cessaram as lutas e em cada momento histórico gestaram novas formas de resistir. E, no caso desta região, o MST $^{5}$ é um destes movimentos, que tem ligaçóes intrínsecas com o processo de lutas pela educação no campo, como vimos.

De acordo Fernandes (2000) ainda na década de 1980, especificamente em 1989 o MST iniciou suas lutas no Estado do Pará. Estes primeiros trabalhadores eram decorrentes de estados como Goiás, Maranhão, Ceará e do espaço Sul e Sudeste do Pará. Contando com a colaboração direta da CPT e alguns Sindicatos de Trabalhadores Rurais a primeira ocupação do MST no Estado do Pará ocorreu no ano de 1990, na Fazenda Ingá, localizada no município de Conceição do Araguaia. Segundo Terence (2013) no decorrer desse período o movimento realizou mais duas ocupaçóes na região, porém devido a "um estranhamento entre as táticas de ocupaçôes" do movimento e dos posseiros estabelecidos na região, atuação do MST deslocou-se para região de Marabá, maior município da região.

Deste a década de 1960 esta região foi permeada por intensos fluxos migratórios, decorrentes de projetos governamentais que se intensificaram ao longo do regime militar. A construção da Belém-Brasília, da Transamazônica e toda propaganda produzida intensificaram tal migração, principalmente da região Nordeste, como destaca Pereira (2013). Porém, o que se observou foi o cerceamento da terra por meio da ocupação de grandes empreses provenientes principalmente da região Sudeste, fechando o cerco aos grupos indígenas e camponeses que aqui viviam ou que estavam em processo migratório. Somente neste período segundo dados da CPT apresentados por Fernandes (2000) 389 foram assassinadas nestes conflitos, em que parte de seus executores foram identificados, mas nem todos condenados.

O primeiro assentamento, fruto da luta em Ingá, surgiria ainda em 1992, ao passo que a luta na fazenda Canarana, também em Conceição do Araguaia, ainda estava em desenvolvimento. As constantes prisóes e perseguiçóes fizeram com que o movimento se desmobilizasse de açóes na região de Marabá, ampliando para outras localidades no Sul e Sudeste do Pará. Tal açóes não desmobilizaram o movimento, que se ampliou em novas frentes de atuação, ao mesmo tempo em que novas páginas de sangue ainda estariam por vir, como no caso do Massacre de Carajás, em $1996^{6}$

O Assentamento Joáo Canuto teve seu processo de lutas iniciado em março de 2006, decorrente diretamente do acampamento estabelecido neste espaço e organizado pelo MST. Segundo o mote documental analisado, entre entrevistas e periódicos de circulação regional, o processo de formação do acampamento teve início em fevereiro de 2006, quando alguns sujeitos se deslocaram de cidades como Xinguara e Rio Maria. Segundo o entrevistado M.M. S, liderança à época, morador do assentamento e integrante do MST desde o final do ano de 1990, sua participação na luta se iniciou quando sua mãe, em razão de uma séries de dificuldades financeiras, passou a fazer parte do movimento, após um convite para uma reunião no vilarejo onde moravam.

\footnotetext{
5 O denominado Movimentos dos Trabalhadores Rurais Sem Terra, o MST tem suas origens no conjunto de articulaçóes entre trabalhadores rurais entre 1979 e 1984, coadunando uma diversidade de segmentos do campo. Foi criado formalmente a partir do I Encontro Nacional de Trabalhadores Sem Terra, em Cascavel-PR, em janeiro de 1984, tendo sido realizado mais de vinte encontros nacionais até o presente. A partir da data de sua criação formal o movimento expandiu-se rapidamente por todo território nacional (CALDART, 2008; FERNANDES, 2000; STÉLIDE, 1997).

6 Em memória ao ocorrido um monumento foi projetado por Oscar Niemayer e inaugurado em 7 se setembro de 1996 em Marabá. O monumento imitava um arado com uma mão, dividindo dois olhos ao fundo. O monumento foi destruído quinze dias depois de sua inauguração por fazendeiros da regiáo.
} 
Tal movimento se repetiu na formação deste acampamento, quando ele e outros companheiros foram para as cidades de Xinguara e Rio Maria à procura famílias carentes que não tinha casa própria ou estavam desempregadas, sendo que esta busca por famílias é conhecida dentro do movimento como "trabalho de base". Após esse trabalho de aproximadamente um mês nessas duas cidades as famílias foram convocadas para irem até a cidade de Sapucaia para de lá se dirigirem até a área que seria ocupada, bem relatado e lembrado por todos os entrevistados:

[...] eu lembro que nós chegamos aqui em fevereiro de dois mil e seis, pra pra essa regiáo e ai viemos pra Xinguara outra turma nossa e foi pra Rio Maria na qual foi eu fui pra na equipe de Rio Maria e ai fizemos o trabalho, eu lembro que foi no dia dez de fevereiro ate o dia oito de março do mesmo ano dois mil e seis, e nós conseguimos ajuntar as famílias e ai no dia nós fizemos a reunião e no dia sete a noite dia sete de Março convocando as famílias a comparecerem no local no dia oito no caso oito de março pra puder sair da cidade que nós estávamos tanto de Xinguara, de Rio Maria já justamente pra área indicada quando nós chegamos em sapucaia já com as famílias que nós tínhamos conseguido ai nós tivemos uma reunião interna da militância ai lá foi que eu fiquei sabendo qual seria a área que no caso a Rio Vermelho e não só eu mais uma boa parte da militância que estava que também não foi todo mundo foi só uma parte mais que já tinha mais um acumulo de conhecimento que já tinha mais um histórico de acompanhamento da organização, ai nós chegamos lá no local no local da que seria a ocupação no caso da Rio Vermelho no dia oito de Março por volta de umas oito da manhã o horário que nós chegamos porem o dia certo que nós seria dia oito mais ai tivemos fazendo uma avaliação de que dia oito era dia oito de março seria dia das mulheres e estava tendo uma mobilização grande em Marabá ai nós decidimos que não que fazer a ocupação no dia nove de março contando de que havia mulheres que estava na mobilizaçáo de Marabá viesse também pra ajudar no processo da ocupação, e tâo tal que a ocupação foi dia nove de março por volta de uma da manhã o da tarde, que nós fizemos a ocupação direta (M.M.S. MILITANTE do MST. 2018).

Imagem 01 - Cobertura do processo de acampamento pela imprensa local.

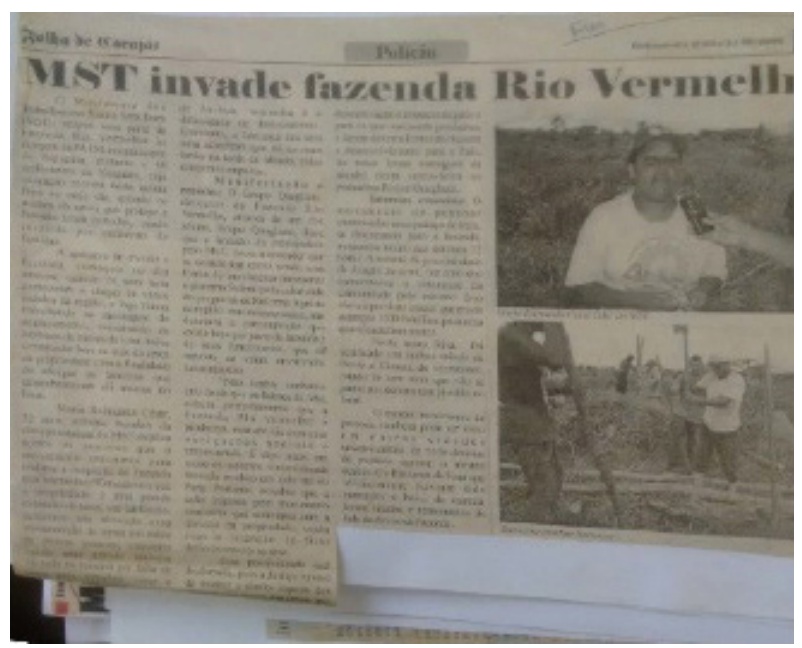

Fonte: Arquivo CPT-Xinguara, 2006.

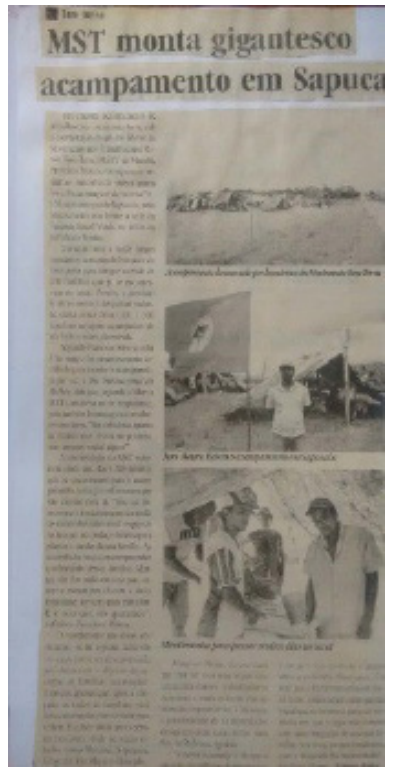


Claramente a imprensa local, como analisado na documentação acima, construiu e articulou a já recorrente ideia da "invasão" e criminalização dos eventos. Os primeiros barracos foram construídos ainda em 2006 na área estipulada, às margens da rodovia, ficando sob a coordenaçáo do MST e agora da liderança local, durante o processo de negociação com INCRA. Após a ocupaçáo, segundo o entrevistado M.M.S, as famílias foram separadas em grupos escolhendo dois representantes, um homem e uma mulher, que ficaram responsáveis para estar repassando aos demais o que era ou náo permitido dentro da comunidade. Conjuntamente foi feita a escolha de um casal em cada grupo para fica responsável pela segurança, um representante da comunidade e duas pessoas ficaram sendo responsáveis pela questáo da saúde e educação.

Interessante observar que, ainda em processo de acampamento e mesmo sem a decisão judicial deferida, o movimento iniciou as tramitaçóes para dar início a existência de um núcleo educacional neste espaço. Porém, em meio a tal processo, com apenas dezoito dias de acampadas as famílias foram obrigadas judicialmente a saírem da área. Sem ter para onde ir foram até a prefeitura pedir um local provisório, o que foi negado, sendo necessário montarem acampamento provisoriamente ao lado da rodoviária da cidade. Depois de quatro meses neste local foram novamente "despejados" devido ao fato da área possui proprietário, se deslocando novamente para outra área, enquanto esperavam pelo processo judicial da fazenda.

Imagem 02 - Cobertura do processo de acampamento pela imprensa local.

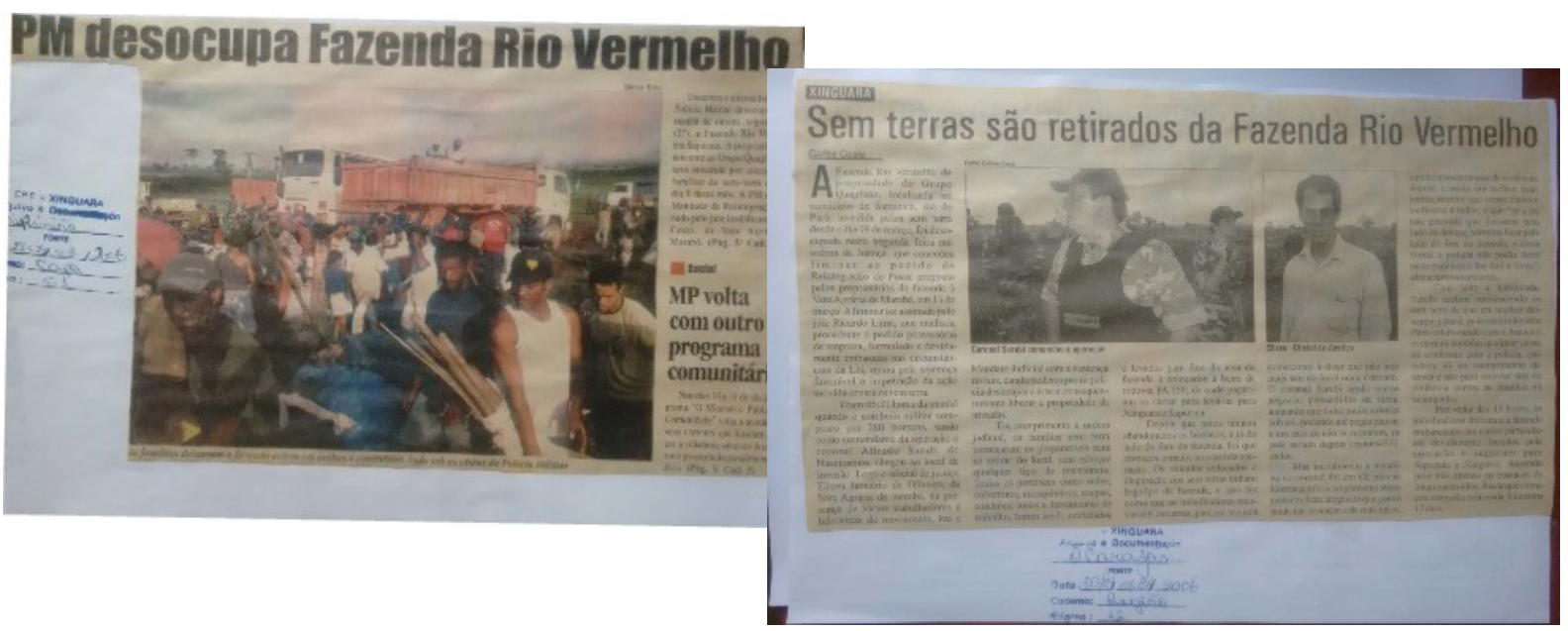

Fonte: Jornal Opinião (2006) e 0 Carajás (2006). Arquivo CPT- Xinguara.

Após terem resolvido a questão legal em relação à área de ocupação as famílias voltaram ao acampamento, retomando a organização interna do movimento e iniciando a distribuição e demais elementos organizativos nos lotes. Inicialmente, como ainda não existiam as demarcaçôes oficiais, foram realizadas pequenas divisóes apenas para que cada família pudesse realizar o plantio básico para subsistência. Este processo durou até 15 de agosto, quando entáo nasceriam o Assentamento João Canuto.

Porém, neste meio tempo, ao retornarem ao acampamento as entrevistas indicam que foram até a prefeitura solicitar a construçáo da escola, momento em que se iniciaria mais um desafio: provar que a existência de uma escola neste espaço era um dever do poder público desta localidade. Isto porque foi alegado que não era obrigação da gestão desta cidade oferecer escola a estas famílias, visto que as mesmas não pertenciam ao município. Diante dessa recusa os assentados se reuniram com a comunidade em busca de auxílio para uma nova abertura de negociaçóes com o poder público local, ocorrendo uma caminhada do acampamento rumo à cidade: 
[...] juntamos todas as famílias de nossa comunidade, criança, veia e fizemos a caminhada até lá na prefeitura, ai o [..] veio acompanhar nós na estrada ainda, eu lembro disso ainda como hoje, quando acompanhou nós na estrada, ele nos disse de que se nós entrasse no município dele, ele ia mandar a polícia meter fogo em nós, ou a população também, porque a população também estava se sentindo ameaçada, ai nós falamos pra ele, que ele pudesse ir lá mandar a polícia dele atirar, ou a comunidade dele, porque nós estava indo atrás daquilo que era de direito nosso, ai eu lembro que quando nós chegamos na escola, ai nós continuamos nossa marcha, ai fomos direto pra escola, padre José de Anchieta, quando nós chegamos lá, eu lembro que teve professores, [...] que pulou o muro da escola com medo de sem terra, e ai teve muitos alunos que se apavoraram, mais justamente porque o prefeito já tinha feito todo o alarde, e ai a gente depois começamos a conversar lá dentro da escola, fizemos uma assembleia só entre nós, e ai depois começou a encostar os professores ne, os alunos, e viram de que tudo aquilo de que tinha sido falado, não era real, ou seja, uma coisa abstrata, e ai a partir dai nós convocamos os professores, só os professores pra uma sala, e conversamos..." (M.M.S. MILITANTE do MST, 2018).

Desfeito todo o mal-entendido, em que claramente a construçáo de uma imagem negativa dos trabalhadores e famílias ocorreu sem um menos contato prévio sobre qualquer real situação, os representantes educacionais receberam a liderança do assentamento. Novamente em meio as negociaçóes, segundo as entrevistas realizadas, a proposta do poder público era a de oferecer transporte para que as crianças pudessem estudar na escola local, o que foi rapidamente negado pelo movimento, visto que queriam justamente que as crianças tivessem a oportunidade de estudar no próprio assentamento. Nenhum acordo foi estabelecido e a reuniáo foi encerrada. Segundo os depoentes somente quando foi levantando dados sobre a quantidade de alunos existentes no assentamento o poder público local asseverou iniciar novos diálogos, ainda com forte oposição de seus membros. Sem o apoio da prefeitura as famílias conseguiram o material e por conta própria construíram a escola e solicitaram a secretaria de educaçáo apenas à contrataçáo dos professores.

Segundo os trâmites legais é de direito ofertar o ensino básico no espaço de vida e trabalho dos sujeitos do campo, assim como dever de fornecer uma instruçáo adequada para que professores do campo lecionem no campo. Neste caso, como em grande parte do país, o ensino é vinculado com materiais e profissionais lotados em instituiçóes públicas urbanas, fato que se repetiu na escola Dom José Gomes .

Mesmo com tal aporte, as aulas foram iniciadas um ano depois, em 2007, devido ao processo de acampamento e, posteriormente, negociação para acesso educacional para o assentamento. Segundo um dos entrevistados "viemos pra uma pra beira da estrada prum local ali conhecido como Tião da venda e aí ficamos lá até o [...] dia quatorze de junho do mesmo ano até fazer o retorno para a fazenda Rio Vermelho [...]” (M.M.S.). Neste ponto é salutar destacar a presença da CPT-Xinguara e a figura de Frei Henri des Roziers. Francês, radicado no Brasil desde a década de 1980, tornou-se uma importante figura na trajetória dos movimentos sociais em todo Sul e Sudeste do Pará, atuando

\footnotetext{
7 Os entrevistados disseram não lembrar quem sugeriu esse nome para escola. De acordo com as informações "Dom José Gomes foi Bispo da Diocese de Chapecó (SC), entre 1968 a 1999, dedicou parte de sua vida eclesiástica na defesa das populaçóes indígenas na sua diocese e no Brasil. Foi presidente do Conselho Indigenista Missionário entre 1979 a 1983 (BRIGHENTI; NÖTZOLD, 2009).
} 
diretamente junto aos sujeitos assim como judicialmente à frente dos tribunais por estes mesmos sujeitos:

naquele ano e foi prejuízo pra nós porque as crianças perderam aquele letivo, por mais, por mais que tivemos um grande apoio naquele período, e aí talvez entra uma das figuras mais, e que mais contribuiu com a gente naquele período e contribuiu até a saída dele aqui da região no caso Frei Henri, o Frei Henri ele foi uma das pessoas que mais contribuíram e com a gente tanto juridicamente como apoio financeiro apoio e político também na figura dele. (M.M.S. MILITANTE do MST, 2018).

Desde seu início, o estabelecimento da escola Dom José Gomes esteve atrelada ao Município de Sapucaia e, embora o local pertence ao município de Xinguara, quem responde pelas questôes da educação é a secretaria de educação de Sapucaia, como podemos constatar através de documentos encontrados na escola do assentamento, como os diários de classe. Depois de alguns meses de muitas cobranças e reclamaçôes a secretaria acatou o pedido e fez a substituição dos professores. Ainda assim os problemas não foram totalmente solucionados. De acordo com a professora D.S. $\mathrm{L}^{8}$, nos primeiros meses ela e os demais professores (as) trabalharam praticamente de forma voluntária, recebendo apenas cem reais mensais. A professora D.S. L assim como o M.M.S relataram que nos primeiros meses de funcionamento da escola foram as famílias que forneceram e preparam a merenda.

A falta de apoio da prefeitura não se configurou como um empecilho para o desenvolvimento de práticas educativas de qualidade, visto que de acordo com os educadores da escola durante seu o período de funcionamento no acampamento o setor de educação do MST prestou todo o apoio pedagógico, tanto aos educadores como para os educandos, conforme ressaltado na fala do M.M.S:

[..] naquele período que nós ocupamos, de 2006 até 2012 foi um dos períodos que eu mais acompanhei em partes, eu lembro que em média a 4 em 4 a seis meses o MST o setor de educação senta né, pra poder traçar novas e novas formas pedagógicas pra transmitir aquilo que é de fundamental importância para os nossos professores e para nossos alunos, no processo de formação das nossas crianças nas áreas de acampamento sempre tem uma pessoa, e ao que seja umas duas três vezes no ano que vai na escola também, vai conversar com os alunos a respeito da organização, eu lembro que eu participei duas vezes dessa, desse processo de formaçấo na escola [..] (M.M.S. MILITANTE do MST, 2018).

Nessas formaçôes, segundo D.S.L, são discutidas as normas do movimento e apresentadas e refletidas as experiências educativas dos professores nas escolas do acampamento e assentamento

\footnotetext{
8 A professora D.S.L. mudou-se para o acampamento no ano de 2007 para trabalhar na escola, a pedido do representante da comunidade. Lecionava numa escola localizada em um assentamento na Fazenda Peruana, no município de Eldorado dos Carajás. Sua inserçáo no movimento ocorreu na época de sua adolescência quando seu pai acampou na Fazenda Macaxeira no município de Curionópolis -Pará.
} 
onde trabalham. A partir da exposição e reflexão debatidas nos encontros são elaboradas novas propostas pedagógicas conforme as dificuldades apontadas, que contribuam para o desenvolvimento de um ensino baseado nos princípios educativos do movimento. A conciliação entre as açôes do movimento e a educação dos acampados é uma preocupação constante do MST. Segundo a professora todas as atividades de protesto, interdiçóes de rodovias realizadas pelos acampados são organizadas de modo que não interrompa a aprendizagem dos alunos.

As aulas no acampamento ocorriam em três turnos: no período diurno funcionavam as turmas da pré-escola, 1 $1^{\mathrm{a}}, 2^{\mathrm{a}}, 3^{\mathrm{a}}, 4^{\mathrm{a}}$ série e no noturno o Encontro de Jovens e Adultos. Segundo os entrevistados as turmas eram bem numerosas, pois, segundo as lideranças, no início da ocupação havia uma média de 300 famílias. Segundo o militante M.M.S. o acampamento chegou a ter um total de 337 famílias, no entanto, à medida que o tempo foi passando esse número foi se reduzindo gradativamente, decorrência do desgaste causado pela demora dos órgáos governamentais em realizar a distribuição dos lotes. Em carta produzida por assentados e divulgado no jornal Diário de Sapucaia, podemos perceber tal situação:

(...) estamos acampados a mais de 8 anos em situaçóes precárias, humilhados ouvindo mentiras por parte de alguns que se dizem ser líder do movimento, cortando cadastro, batendo no povo e pedindo dinheiro, ou damos ou eles ameaçam cortar o cadastro, é um verdadeiro inferno, isso é um absurdo para o ser humano que precisa ganhar um pedaço de terra pra sobreviver(... $)^{9}$.

A fala acima é um fragmento da carta coletiva escrita pelas lideranças do acampamento como forma de protesto contra a demora do INCRA em regularizar os lotes de terra. Além da carta os acampados realizaram ainda bloqueios na rodovia BR-155. Ao longo de nove anos ocupações, protestos e bloqueios foram realizados constantemente pelos acampados, até que no ano de 2015 foi oficialmente criado pelo INCRA o assentamento, através do processo no 54600.000187/2015, ocorrido por meio de uma permuta entre o fazendeiro que reivindicavam a posse da área e a União conforme relata o trecho a seguir:

O PDS “João Canuto II" foi obtido por meio de permuta em área pública do imóvel denominado de Retiro Guerobal com área de 3,6 mil hectares, localizado no município de Xinguara, e tem capacidade para o assentamento de 142 famílias de trabalhadores rurais ${ }^{10}$.

O assentamento encontra-se localizado na BR-155, sentido Marabá, segundo pela estrada que liga Xinguara ao distrito São José. O percurso é realizado em parte por via asfaltada e um segundo trecho de cerca de $5 \mathrm{~km}$ de estrada de terra, entre a entrada e o assentamento.

9 Trecho retirado da carta enviada por líderes do MST à redaçáo do Diário de Sapucaia, publicada por Gustavo Marcos, no dia 20 de novembro de 2013.

10 Fragmento retirado do site oficial do INCRA. Disponível em: <http://www.incra.gov.br/noticias/incra-cria-

primeiro-projeto-de-desenvolvimento-sustentavel-do-sul-do-para> . Acesso em: agosto de 20019. Fonte: Arquivo pessoal, 2018. 

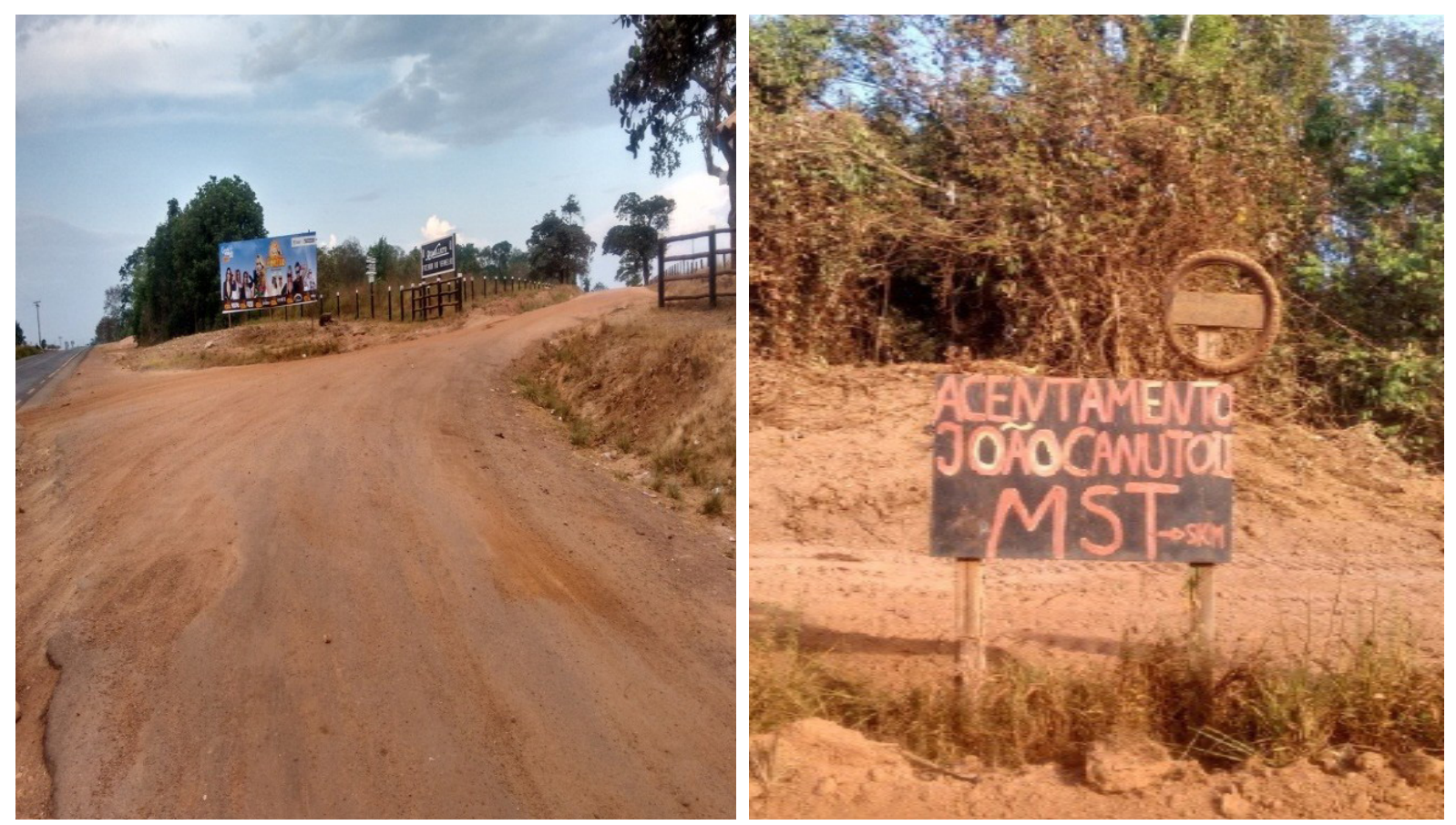

Após a efetivação da troca da área as famílias foram deslocadas do local onde estavam acampadas, a partir de então fizeram a distribuição dos lotes. Cada família recebeu um lote de 5 alqueires de terra, o que por meio da documentação analisada não puderam ser efetivamente explorados, visto que todo a ajuda e manutenção necessária não foram realizadas, conforme previsto no processo de assentamento de reforma agrária. Sem esta ajuda financeira muitos assentados acabaram deixando o assentamento, visto que as dificuldades ultrapassaram as possibilidades de volta e fixação no campo. Em grande parte, os assentados que estáo tentando resistir sobrevivem da agricultura de subsistência e outras atividades realizadas, mas longe de todas as possibilidades e potencialidades que a vida no campo permite.

Dentre as muitas dificuldades, os assentados indicaram que não conseguem vender a produção excedente, devido as dificuldades da logística até as cidades para levar os produtos, assim como o deslocamento também se torna difícil pelos próprios afazeres cotidianos. Logo, tais dificuldades também marcaram a trajetória da oferta de ensino neste espaço, que perpassam da estruturação física até a escolha dos métodos e materiais adequados para esta modalidade de ensino. De forma geral, o que já pudemos observar na tessitura das fontes é que neste processo houve um rompimento com os princípios educativos organizados pelos materiais dos movimentos sociais do campo.

De acordo com Salomão Hage (2015) o movimento educação no Campo no estado do Pará teve início no ano de 2003, após reunião na "antiga Escola Agrotécnica Federal de Castanhal" onde se encontravam presentes representantes dos movimentos sindicais do campo, universidades e sociedade civil. A partir deste encontro, exatamente um ano depois, foi criado o Fórum Permanente de Educação no Campo (FPEC) responsável por coordenar e organizar as açóes do movimento no estado. Segundo este autor:

O Fórum Paraense de Educação do Campo, movimento que aglutina entidades da sociedade civil, movimentos sociais, instituiçóes de ensino, pesquisa, órgãos 
governamentais de fomento ao desenvolvimento e da área educacional da sociedade paraense, que, compartilhando princípios, valores e concepçóes político-pedagógicas, buscam defender, implementar, apoiar e fortalecer políticas públicas, estratégias e experiências de educação do campo e desenvolvimento rural com qualidade social para todos/as cidadáos/âs paraenses, sobretudo para as populaçóes do campo, aqui entendidas como: agricultores/as familiares, indígenas, quilombolas, extrativistas, ribeirinhos e pescadores. (HAGE, 2015, p. 25)

O FPEC tem procurado desenvolver ações que possibilitem a ampliação e interiorização do debate sobre a educação no campo no território paraense, através da realização e divulgação de eventos que promovam a socialização e reflexão sobre a realidade educacional das diversas regióes que compóe o estado. Nesse sentido, foram realizados vários encontros e seminários para elaborar discutir a falta de políticas públicas e problematizando questôes ligadas à educação do/no campo. A partir da criação do fórum muitas transformaçôes puderam ser observadas, mas aquém das realiza necessidades de nossa escolarização no campo. Nesse aspecto, com base nas propostas de educação no campo materializadas na forma de lei no artigo 28 da LDBN no 9.394/96 e na Resoluçáo CNE/ CEB no 01/2002 Parecer CNE/ CEB n.36, gerou-se a necessidade em pesquisar e analisar como está ocorrendo à educação do campo e o ensino de história numa escola localizada dentro de um assentamento na zona rural no município de Xinguara.

Diante de toda essa complexidade da questão agrária na região e tendo em vista que de acordo com os PCNs (1997), um dos objetivos da disciplina de História no ensino fundamental é possibilitar que os alunos sejam capazes de "questionar sua realidade, identificando alguns de seus problemas e refletindo sobre algumas de suas possíveis soluçóes, reconhecendo formas de atuação políticas institucionais e organizaçóes coletivas da sociedade civil", fez-se necessário pesquisar como está ocorrendo o ensino aprendizagem na Escola Municipal de Ensino Fundamental Dom José Gomes.

No primeiro momento realizamos um contato prévio com os agentes educacionais neste assentamento, em que apresentamos o projeto ${ }^{11}$ em desenvolvimento e tivemos uma conversa com duas professoras as quais ficaram interessadas. Aceitando participar do trabalho, concederam as entrevistas, visto que se mostraram preocupadas com as questóes que norteavam seu trabalho e as dificuldades que ameavam sua própria continuidade. Durante a conversa as professoras comentaram que na construção dos planos de ensinos anuais realizados na sede do município há uma priorização dos interesses da populaçáo urbana. Esta imposiçáo acaba ignorando a diversidade existente entre o espaço rural e urbano dificultando a efetivação da educação voltada para o campo. No decorrer da entrevista com a professora " $\mathrm{B}$ " ao conversarmos sobre a interação professor-aluno e comunidade foram levantados questionamento sobre qual a importância de ter uma escola no assentamento:

Pra mim e de suma importância porque, se temos agricultores, se temos uma assentamento com famílias, pais, crianças, adolescentes, é de suma importância a questáo de uma escola dentro desse assentamento, porque a disponibilidade pra, pra família permanecer ali no campo é essa questão, ai se não temos a escola igual aqui, eu até já questionei isso também da nossa escola funcionar, da educação infantil até o quinto ano, Por que que os nossos governantes, o nosso poder

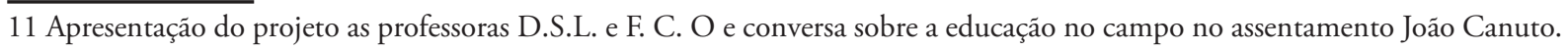


público não dá a chance pros nossos alunos, pros nossos agricultores continuarem no campo pelo menos no nível até o nono ano? Com escolas e..., profissionais formados agindo dentro desse assentamento, dentro dessa escola pra para que nossos jovens não saiam pra que nossas crianças com as famílias tenham que tá saindo também. Então assim acaba a educação no campo sendo fraca pras nossos crianças devido a isso, aquelas crianças não terem paradeiro, aquelas famílias não terem paradeiro fica no assentamento, vão pra outro, o outro não tem escola, não tem ônibus pra ir até a cidade, agora mesmo a minha filha, to sem meus filhos tarem aqui em casa porque a nossa escolinha aqui só funciona até o quinto ano[...] ( PROFESSORA-B, F. C. O, 2018).

A resposta da professora reafirma tudo aquilo que tanto o MST como os demais movimentos sociais do campo têm insistido em cobrar do Estado. Na fala da professora é possível notar outro aspecto bastante cobrado pelos movimentos, que é a oferta de uma educação em todos os níveis de ensino que ocorra prioritariamente no campo e que para, além disso, sirva aos filhos dos assentados, de modo que o saber apreendido os ajude a lidar com a terra favorecendo sua permanência no local onde vivem. É válido ressaltar que tal aspecto está contido na resolução no ${ }^{\circ} 2$ das diretrizes aprovada em 2008. Segundo Caldart (2004) a luta por políticas públicas que atenda a populaçáo no/do campo é um direito e deve ser consolidada no local de origem e pensada a partir dele.

Outra preocupação da população é com o ensino do $6^{\circ}$ ao $9^{\circ}$ ano e ensino Médio, ofertados somente na cidade de Sapucaia. Ao concluírem o ensino fundamental I as crianças são deslocadas para a Escola Padre José de Anchieta, escola núcleo do Município, por meio do transporte e após o fundamental II são transferidas para escola estadual Paulo Freire, como podemos observar através da fala de uma das professoras do assentamento:

[...] a minha filha tá fazendo o sexto ano e aí não teve como ela ficar indo no ônibus pra cidade porque o ônibus sai 10 horas da manhã, pra aula que é à tarde, e retorna aqui pro assentamento 10: 30, já teve questão de retornar 11:30, 11 horas da noite, porque chega o período do inverno o ônibus quebra na estrada, os buracos tá entendendo? O horário dele chegar normal é 7 da noite, eu sei que, pra a gente tem problemas até maiores, igual quando eu questiono nas formaçôes que eu comento, sempre as pessoas falam, há ainda tá é bom, porque tem lugar fulano de tal que a criança anda num sei quantos quilômetros tá entendendo? Invés de procurar uma melhora acha que aquilo ali ainda tá e gratificante, entâo é assim, é de suma importância, pra mim enquanto educadora, quanto professora, é muito de muita importância a escola dentro de uma área do assentamento por conta da disponibilidade que, que os nossos agricultores tem com as crianças com os filhos para poder permanecer no campo (PROFESSORA-B, F. C. O, 2018).

Para que o ensino cumpra com a proposta de uma educação específica visando atender uma demanda própria do sujeito do campo é preciso que o/a professor/a também ocupem esse espaço e participem da construção do currículo Escolar para o Campo, pois quando isso não ocorre o ensino continuará acontecendo fora da realidade local, de forma desconexa aos interesses dos movimentos sociais por uma educação do/no campo continuando atender somente aos alunos urbanos, baseado em uma seleção de conteúdos que atenda os interesses da cidade e desconectado da realidade do 
aluno que vive fora desse espaço. Freire (2005) afirma que esse modelo de educação possui concepção bancária, onde não se promovem reflexôes para a construção do conhecimento, desvinculada do saber, e com base na reproduçáo. A escola que possui o poder de transformar e promove o enquadramento do sujeito em um modelo de educação colocando os educandos em condiçóes submissas transformando-os em agentes passivos, se tornando oprimidos, criando a ideia de que a problematização e a reflexão seja uma arma perigosa que poderá ser utilizada contra o opressor.

Nesta mesma perspectiva o entrevistado M. M. S (2018) contribui para nossa análise quando cita uma frase de cunho popular utilizada pelos patrocinadores do agronegócio, reafirmando o resultado de uma educaçáo voltada para fornecer a mão de obra que promove o grande capital. E a partir desta reflexão deixa claro quais são os princípios defendidos pelo MST para a educação do/no campo. Segundo o entrevistado o movimento não busca atender o mercado de trabalho, a educação defendida aqui está para além da formação técnica, ela deve ser ofertada visando à preparação do indivíduo para romper com as barreiras imposta pelas desigualdades sociais, promovendo a libertação dos sujeitos que ao longo da história foram sendo excluídos:

tem uma metáfora, e eu nem considero metáfora, eu entendo de que isso é um fato real, pro grande capital o funcionário bom é o funcionário analfabeto né, a pessoa boa pro mercado é a pessoa que náo tem conhecimento, e a pessoa que tem conhecimento mais não tem disposição pra defender aquilo que ele pensa, a escola do campo por exemplo, ela vai além disso, por exemplo, eu sempre imagino de que a educação no campo é uma das é um , é [...] uma das chamada educaçáo mesmo que consegue preparar o indivíduo pra vida intendeu? Ele não prepara a pessoa pro mercado de trabalho, não, nesse sentido, por exemplo, eu sempre gostei de ter como princípio o estudo, apesar de que eu não tenho muita vocaçáo pra estudar na escola mais eu sempre tive o entendimento de que a única coisa que possa nos libertar é o conhecimento, e a escola do campo ela vai além disso ela vai além do conhecimento técnico, ela vai em busca do conhecimento da libertação do indivíduo, (M.M.S. MILITANTE do MST, 2018)

Para Peripolli e Zoia (2011), "O desafio maior está em compreender que as questôes das escolas do campo estão colocadas fora delas. Ou seja, são decorrentes de outros aspectos que dizem respeito ao campo". Segundo os autores a educação no campo necessita de políticas públicas que busque atender as suas especificidades e não querer adequá-las ao meio urbano, as quais devem estar direcionadas a atender os interesses de quem vive e trabalha na terra.

A referida escola aqui em mote, qual seja, a Escola Municipal de Ensino Fundamental Dom José Gomes está localizada na vila do assentamento João Canuto, sendo sua localidade pertencente ao Município de Xinguara, mas a educação fica sob responsabilidade do Município de Sapucaia. Seu funcionamento ocorre em um prédio dentro do assentamento, em espaço coletivo. É uma construção de tábuas, forrada para comportar a climatizaçao, as salas são de pisos com cimento queimado porém bem esburacado. A sala do maternal ao $2^{\circ}$ ano receberam recentimente mesas e cadeiras, a de $3^{\circ}$ ao $5^{\circ}$ ano ainda se encontra com cadeira de madeiras com braço. A sala da secretaria possui computador, mas não tem acesso a internete, segundo as professoras as atividades são xerocadas, sendo que as series de $1^{\circ}$ ao $5^{\circ}$ ano recebem o livro didático. 

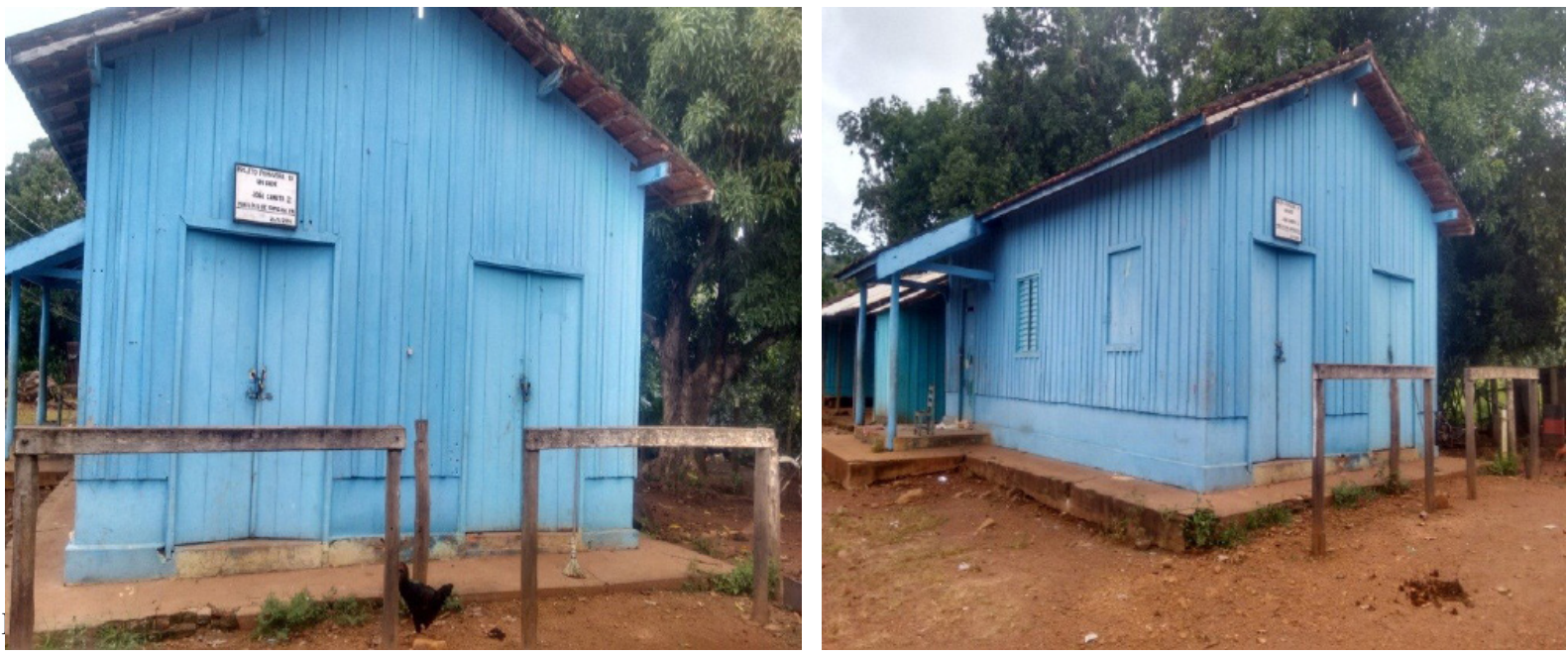

Segundo a professoras do assentamento a secretaria de educação quase sempre disponibiliza todos os materias que elas necessitam, sendo "a maior dificuldade é só mesmo a falta de acompanhamento, assim, praticamente diário, pelo menos uma, duas ou três vezes, coordenador tá junto com a gente, acompanhando né? Mais, material, graças a Deus, nós conseguimos correr atrás, e conseguimos direto, dificilmente falta". A professora "B" relata ter um pouco de dificuldade para organizar os materiais, pois gosta de trabalhar dentro da proposta de formação do PNAIC, e que na Zona rural tudo fica mais difícil para produzir os materiais necessários a alfabetização e esta dificuldade acentua ainda mais quando se trabalha com uma sala multisseriada.

No caso da professora "B" que trabalha do maternal ao $2^{\circ}$ ano a diversidade de níveis de conhecimento existentes entre as crianças é muito grande exigindo muito da professora, tanto em sala de aula como fora dela:

A gente utiliza material que nós mesmos pesquisamos ne e com as formaçôes do Pacto ${ }^{12}$ também eles nos auxilia muito ne dando ideias, e assim a questão da organizaçấo e meio complicado por que pra cá pra zona rural tudo e mais difícil, tudo, tudo, tudo, tudo é mais difícil,..[...] E assim eu gosto de separa meus materiais conforme os níveis dos meus alunos ne, primeiro ano segundo ano a cada etapa a gente faz aquele diagnostico ne eu gosto de trabalhar com a questão do diagnóstico dos meus alunos e a gente vai evoluindo o trabalho e separando o material todo por níveis, a gente trabalha com as tarefinhas xerocopiadas ne, trabalha e a gente monta, eu gosto de montar material em casa mesmo ne, jogos de silabas ne jogos de rolinho de papel, esses joguinhos que a gente elabora joguinhos pedagógicos que a gente pesquisa que são a mão na roda, entấo eu vejo a questão do níveis de, dos níveis que eles estão e elaboro tantas atividades como o material pedagógico por níveis, assim que eu faço minha turminha. (PROFESSORA-B, F. C. O, 2018).

A estrutura da escola foi montada a partir de adaptaçóes das antigas casas do retiro da fazenda onde residiam os trabalhadores, como era duas casas próximas transformaram-nas em duas salas 
de aula, secretaria e uma pequena biblioteca. Para atender as necessidades básicas dos educandos e educadores adaptaram os banheiros, construíram uma cozinha e galpóes onde funcionam como refeitório, espaço de socialização entre as turmas, eventos escolares que envolve as famílias e reunióes escolares e de interesses da comunidade.

De acordo com o censo no ano de 2017 funcionavam em dois períodos com turmas de educação infantil ao $5^{\circ}$ ano, com o número de 11 funcionários no total, sendo que as aulas são ministradas por duas professoras com formação em pedagogia e dois auxiliares com formação em nível médio. As turmas são multisseriadas, com 13 crianças matriculadas no ano de 2017 na educação infantil, 32 de $1^{\circ}$ ao $5^{\circ}$ ano e 82 de EJA, números segundo informaçóes obtidas no INEP. Porém, segundo as fontes as turmas de EJA só funcionaram nos anos anteriores ao assentamento e atualmente a escola não atende a este público. Em 2018 a escola funciona com o número de oito funcionário e atende aproximadamente 60 crianças do maternal ao $5^{\circ}$ ano, funcionando em um único turno.

\section{CONSIDERAÇÕES FINAIS}

O acampamento/assentamento João Canuto é o desdobramento de Lutas por Reformas Agrárias na Regiáo Sul do Pará, as famílias assentadas, atualmente, permaneceram acampadas entre ameaças e despejos, aproximadamente nove anos, em uma área da União sob domínio de um poderoso grupo do ramo agropecuária na regiâo próximo a cidade de Sapucaia. O processo de acampamento iniciou em março do ano de 2006 e a situação das famílias dos acampados só foram resolvidas em 15 de agosto de 2015. A Escola Dom José Gomes foi fundada a partir deste contexto desenvolvendo junto ao acampamento, após os integrantes do Movimento dos Trabalhadores Sem Terra reivindicarem seus direitos tendo por base a LDBN e os princípios dos movimentos sociais da educaçáo do/no campo, que lutam por reduzir as injustiças e as desigualdades sociais existentes no Brasil.

Durante o processo de ocupação que marcou o início da construção e desenvolvimento da Escola Dom Jose Gomes no ano de 2007 construída dentro do acampamento, recebeu apoio do setor da educação do movimento localizado na região. Os quais contribuíram com materiais e formaçóes pedagógicas para os professores que atuavam na escola, os encontros eram realizados com base nos princípios da educação do/no campo. Atualmente a escola se encontra na vila do assentamento, sob a coordenação da secretaria de educação de Sapucaia e não recebem mais as formaçóes.

\section{REFERÊNCIAS BIBLIOGRÁFICAS}

BRASIL, Ministério da Educação. Secretaria de Educação Continuada, Alfabetização e Diversidade. Educação do Campo: Diferenças rompendo paradigmas. Caderno SECAD. 2. Brasília: SECAD, 2007.

CALAZANS, Maria Julieta Costa. Para compreender a educação do Estado no meio rural - traços de uma trajetória. In: Jacques Therrien e Maria Nobre Damasceno (coords.). Educação e Escola no campo. Campinas: Papirus, 1993.

CALDART, R., S. Por uma Educação do Campo: Traços de uma identidade em construção. In: ARROYO, M.G.; MOLINA, M. C. (org.). Por uma Educação do Campo. Petrópolis, RJ: Vozes, 2004. 
CALDART, R.S. Sobre educação do campo. In: FERNANDES, B.M.; OLIVEIRA, C. J.; SANTOS, C. A.; DUARTE, C. S.; MICHELOTTI, F.; MOLINA, M.C.; CALDART, R.S. Educação do campo: campo políticas públicas - educação. Brasília: Incra; MDA, 2008. DUART, Clarice Seixas. A Constitucionalidade do Direito à Educação dos Povos do Campo Educação do Campo: campo- políticas públicas - educação In: FERNANDES, Bernardo Mançano et al. Brasília: Incra; MDA, 2008.

FERNANDES, B. M. A formação do MST no Brasil. Rio de Janeiro: Petrópolis, 2000.

. Diretrizes de uma Caminhada. In: ARROYO, M.G, CALDART, R.S., MOLINA, M.C (orgs.) Por uma Educação do Campo. Petrópolis, RJ: Vozes,2004. p. 133 - 146.

HAGE, Salomão. Movimento de educação do campo na Amazônia paraense: açóes e reflexóes que articulam protagonismo, precarização e regulação. 37a Reunião Nacional da ANPEd - 04 a 08 de outubro de 2015, UFSC - Florianópolis.

LEITE, Sergio Celani. "Urbanização do processo escolar rural. Educação e Filosofia,10,285-298, ju/ dez.1996.

MOLINA, Mônica Castagna (org.). Educação do Campo e Pesquisa. Brasil. Ministério do Desenvolvimento Agrário, 2006.

MUNARIM, Antônio. Trajetória do movimento nacional de educação do campo no Brasil. In: Revista do Centro de Educação da Universidade Federal de Santa Maria, Vol. 33, n. 1, p. 57- 72. Jan./Abr. 2008.

PASSADOR, C. S. Um estudo do projeto escola campo - casas familiar rural (1990-2002) do Estado do Paraná: a pedagogia da alternância como referencial de permanência. Tese apresentada ao Curso de PósGraduação em Educação da Universidade de São Paulo. 2003.

PEREIRA, Airton dos Reis. A luta pela terra sul e sudeste no do Pará: migraçóes violência no campo. Tese (doutorado em história). Programa de Pós-graduação em História. Recife (PE). Universidade Federal de Pernambuco, 2013.

PERIPOLLI, Odimar João; ZOIA, Alceu. O Fechamento das Escolas do Campo: O anúncio do fim das comunidades rurais/camponesas. Disponível em <http://sinop.unemat.br/projetos/revista/index.php/educacao/article/viewFile/435/273>.Acess o em:Julho de 2018. 